\title{
Influence of different power densities during polymerization on the color of composite resins
}

\author{
Brunelly Cardoso de Jesus Santos ${ }^{1}$, Jefferson Chaves Moreira ${ }^{2}$ \\ Yasmin Alves do Nascimento ${ }^{3}$, Daniel Maranha da Rocha ${ }^{3}$, \\ Adriano Augusto Melo de Mendonça ${ }^{3}$, Lycia Gardenia dos Santos Oliveira ${ }^{3}$, \\ Eduardo Bresciani ${ }^{2}$, Daiana Conceição Broll Repeke ${ }^{3}$, Flavia Pardo Salata Nahsan ${ }^{3}$
}

\footnotetext{
${ }^{1}$ Federal University of Sergipe, Department of Dentistry, Street Cláudio Batista s/n, Zip Code: 49060-676, Sergipe, Aracaju, Brazil.

${ }^{2}$ São Paulo State University (Unesp), Institute of Science and Technology, Department of Restorative Dentistry, Avenue Engenheiro Francisco José Longo, $n^{\circ} 777$, Zip Code: 12245-000, São Paulo, São José dos Campos, Brazil.

${ }^{3}$ Federal University of Sergipe, Program in Dentistry, Street Cláudio Batista s/n, Zip Code: 49060-676, Sergipe, Aracaju, Brazil.

e-mail: chaves.moreira@unesp.br, brunellycardoso1@gmail.com, amin.odonto@gmail.com,drmaranha@hotmail.com, adri_amm@yahoo.com.br, lycia_gso@hotmail.com, eduardo.bresciani@unesp.br, daiana@brollortodontia.com.br, flavia_odonto@hotmail.com
}

\section{ABSTRACT}

This study evaluated the influence of different levels of power density on resin polymerization in the staining of composite resins. Thirty-six specimens were made with composite resin (Z350 3M ESPE) with cylindrical Teflon matrix ( $8 \mathrm{~mm}$ X $1 \mathrm{~mm})$. The light curing was performed with different degrees of power density for each group $(\mathrm{n}=12): 300 \mathrm{~mW} / \mathrm{cm}^{2}, 700 \mathrm{~mW} / \mathrm{cm}^{2}$ e $1000 \mathrm{~mW} / \mathrm{cm}^{2}$. Afterwards, the specimens had their color checked, with the help of a spectrophotometer and immersed in coffee solution during 7 days. After, a new measuring was done (CIEL*a*b* color system). Results showed, for $\Delta \mathrm{a}$, only G1000 group obtained a significantly lower value, and the same result was found in the evaluation of $\Delta \mathrm{b}$. For $\Delta \mathrm{E}$ and $\Delta \mathrm{L}$, no significant differences were found between groups. It is concluded that, low and medium power density entails more reddish and bluish composite resin, while the specimens submitted to high power density and then immersed in coffee did not present color change in a short term.

Keywords: Composite resin. Staining. Light curing.

\section{INTRODUCTION}

The use of composite resins has increased significantly over the last years and currently is the major dental material for direct restorations [1], which is due to the optimization of physical and mechanical properties [13]. Despite its good performance among some limitations, this material requires an adequate polymerization, otherwise, it may present extrinsic and intrinsic staining [2-8].

Most resin composites used today in Dentistry are presented initially as monomers converted into polymer chains using light sources [9]. There is a direct relationship between the degree of conversion of monomers and the longevity of restorations $[10,11]$. A satisfactory polymerization provides resins with good biocompatibility, hardness, physicochemical properties and resistance to masticatory forces to which they are subjected $[11,13]$. It also provides greater aesthetic stability, because an insufficient cure induces higher water absorption and incorporation of substances $[3,12,14]$. Overall, the change of resin color makes restorative cycles to be initiated early $[8,15]$.

The color stability of composite resins depends on the degree of conversion of monomers into polymers throughout a sufficient polymerization $[8,16,17]$ and it is affected by the system and the technical condition of polymerization [18]. The delivered radiant exposure and the power density of the photopolymerizer should agree with the energy requirement of the resin so there is a complete conversion of monomers into polymers $[19,20]$. The higher the power density, the higher the number of photons and the greater is the depth and effectiveness of polymerization [21].

The insufficient conversion of monomers into polymers may result in the staining of composite resins 
$[11,12,14,22,23]$. Thus, different polymerization techniques provide higher or lower light intensity to the composite.

However, there are no studies in the scientific literature assessing the influence of different power densities specifically on the staining of composite resins.

In this light, it is appropriate to assess the direct influence of different power densities and the consequent degree of conversion on composite resins subjected to staining after immersion in dye beverages.

\section{MATERIALS AND METHODS}

\subsection{Preparation of specimens}

Thirty-six composite resin (Charisma Diamond, Kulzer, Hanau, Germany) specimens were produced, with 12 specimens for each group.

The sample was calculated at $\alpha=0.5,96 \%$ test power, and $n=12$ teeth per group.

To produce the samples, a Teflon matrix was used, with an internal diameter of $8 \mathrm{~mm}$ and a thickness of $1 \mathrm{~mm}$. The resin was inserted in a single increment in the matrix hole and the resin was pressed with the help of polyester strips in the edges of the matrix to prevent excesses. Photopolymerization occurred with different power densities according to the groups suggested in the study.

The same operator produced all specimens in a laboratory, with a temperature of $23^{\circ} \mathrm{C}$.

\subsection{Groups}

The photopolymerizer used was the VALO Colors Fucsia (Ultradent, South Jordan, USA), which presents fixed power density emission, therefore, plastic cylinder devices were produced with the same diameter of the light point of the device but with different lengths, aiming to modulate the power density to reach the composite resin samples.

The power density values of each group were G300 (300mW/cm²), G700 (700mW/cm²), and G1000 $\left(1000 \mathrm{~mW} / \mathrm{cm}^{2}\right)$. The power density was properly verified before photopolymerization with a radiometer (RD7, ECEL, Ribeirão Preto, São Paulo, Brazil) and the samples were separated into the three different groups.

During the photopolymerization process, the appliance was positioned with the point centered in the samples so the entire extension of the resin was polymerized for 10 seconds.

\subsection{Storage}

The specimens were stored immersed in deionized water, in a plastic recipient, with separated compartments numbered according to each group, for 24 hours, and maintained in a $37^{\circ} \mathrm{C}$ stove.

After 24 hours, the color and opacity of each sample were assessed three times with an X-Rite Color 962 spectrophotometer (Danaher Corporation, Michigan, USA), and the final result was the mean of the three $\left(\mathrm{L}^{*}, \mathrm{a}^{*}\right.$, and $\left.\mathrm{b}^{*}\right)$ values and the mean of the three opacity values. The CIEL*a*b* was the analysis system.

After the initial registration of color, the samples were immersed in a coffee solution prepared with $25 \mathrm{~g}$ of instant coffee (Nescafé Tradição, Nestlé Brasil Ltd., Araras, São Paulo, Brazil) and $100 \mathrm{~mL}$ of water, for seven days in a $37^{\circ} \mathrm{C}$ stove.

After this interval, the resins were removed from the stove, washed in a recipient with water, and dried with absorbent towels. After drying, the color was reassessed with the X-Rite 962 spectrophotometer (Grand Rapids, Michigan, USA) with three repetitions per specimen for the final color reading.

\section{4 vStatistical analysis}

T-paired tests were performed to verify potential differences in the initial and final conditions for each parameter of the study. Two-way ANOVA was applied with repeated measures to verify the presence of differences between the conditions studied considering the time (before and after darkening) and power of the photopolymerizer, as well as the influence of the interaction of these factors. Lastly, one-way ANOVA was performed to compare the Delta results obtained for each light power used $(\mathrm{p}<0.05)$. 


\section{RESULTS}

For $\Delta$ a, the value was significantly lower for G1000 (2.9) when compared to groups G700 (5.3) and G300 (4.9).

Similarly, for $\Delta$ b, only G1000 (10) was significantly different from the other two groups (G700=2.25 and $\mathrm{G} 300=0.26$ ).

There were no differences among the groups for both $\Delta \mathrm{E}$ and $\Delta \mathrm{L}$.

Table 1: Values and standard deviation related to $\Delta \mathrm{E}, \Delta \mathrm{L}, \Delta \mathrm{a}$, and $\Delta \mathrm{b}$ in the different power densities of each group.

\begin{tabular}{lcccc}
\hline Groups & $\Delta \mathrm{E}(\mathrm{SD})^{*}$ & $\Delta \mathrm{L}(\mathrm{SD})^{*}$ & $\Delta \mathrm{a}(\mathrm{SD})^{*}$ & $\Delta \mathrm{b}(\mathrm{SD})^{*}$ \\
\hline $\mathrm{G} 1000$ & $15( \pm 4,3)^{\mathrm{f}}$ & $-10,2( \pm 2,0)^{\mathrm{a}}$ & $2,9( \pm 0,86)^{\mathrm{b}}$ & $10( \pm 5,2)^{\mathrm{c}}$ \\
\hline $\mathrm{G} 700$ & $13,5( \pm 2,9)^{\mathrm{f}}$ & $-12( \pm 2,8)^{\mathrm{a}}$ & $5,3( \pm 0,5)^{\mathrm{c}}$ & $2,25( \pm 2,2)^{\mathrm{a}}$ \\
\hline $\mathrm{G} 300$ & $13( \pm 1,8)^{\mathrm{f}}$ & $-11,8( \pm 1,9)^{\mathrm{a}}$ & $4,9( \pm 0,73)^{\mathrm{c}}$ & $0,26( \pm 2,65)^{\mathrm{a}}$
\end{tabular}

G1000- Light-cured specimens with a power density of $1000 \mathrm{~mW} / \mathrm{cm}^{2}$, G700- Light-cured specimens with a power density of $700 \mathrm{~mW} / \mathrm{cm}^{2}$, G300- Light-cured specimens with a power density of $300 \mathrm{~mW} / \mathrm{cm}^{2}$

SD-Standard Deviation.*Different letters between columns show significantly diferente statistics $(p<0.05)$. Annova to 1 Criterion and Paired T Test $(p<0,05)$.

\section{DISCUSSION}

The present study assessed the influence of different power densities on the color change of composite resins, after immersion in coffee. Considering the results, there were statistically significant differences. Thus, the null hypothesis should be rejected.

The International Commission of L'Eclairage developed the system to measure colors based on human perception (CIE L*, $\left.a^{*}, b^{*}\right)$. The variable $\mathrm{L}^{*}$ corresponds to the black-white luminosity coordinate, $\mathrm{a}^{*}$ indicates the color coordinate along the red-green axis, and $\mathrm{b}^{*}$ indicates the color coordinate along the yellowblue axis $[19,20]$. A positive $\Delta \mathrm{L}$ value means that the object tends to white (brighter) and negative $\Delta \mathrm{b}$ and $\Delta$ a values mean that the tooth tends to be less yellow and less red, respectively [21].

The $\Delta \mathrm{a}$ values in the present study were lower for G1000 when compared to the other two groups, showing a more reddish color direction for G700 and G300. Although the present study found the $\Delta$ a value similar to G1000, the data in the study by Imai et al. 2013 with indirect resin after immersion in tea and polymerization with different systems showed less reddish samples after immersion in tea. The similarity of values only in G1000 may hypothetically be due to the polymerization with higher power density, with a greater conversion of monomers into polymers [12, 14, 22].

Composite resins, after polymerization, change color due to the presence of photoinitiator amines such as camphorquinone (CQ) [23]. In the present study, the lowest $\Delta b$ values were found for G700 and G300, indicating a more bluish color tendency when compared to G1000. Considering CQ provides a more yellowish color for composite resins after polymerization with high power density, it is assumed that such CQ may have had more influence on the color than staining with coffee after seven days. Similar to the specimens of group G1000 in the present study, IMAI et al. 2013 [10] obtained more yellowish samples when immersed in tea.

The degree of conversion is related to be associated with composite resin staining [24, 25 ]. However, in a study [24] using Fourier transform infrared spectroscopy to evaluate the degree of conversion by light-curing units (LCUs), the authors affirm there is no correlation among degree of conversion and superficial staining. Soares et al. (2013) [26] showed that the soft-start light activation results in chemical degradation of organic matrix in resin composite. In this study the authors did not evaluated the degree of conversion, but the use of medium and low power density resulted in color alteration of the composite resin. Thus, considering the scientific literature, the light curing mode might interfere in the composite resin staining susceptibility. 
In a study performed with composite resins immersed in tea and distilled water, IMAI et al. 2013 [10] showed that immersion in water did not change the brightness $\left(\mathrm{L}^{*}\right)$ of the composite resin but immersion in tea decreased these values, reducing brightness. In the present study, when comparing the three groups, the $\Delta \mathrm{L}$ values did not differ despite the lower values of $\mathrm{G} 300$ and $\mathrm{G} 700$, tending to less bright specimens.

Although the $\Delta \mathrm{a}$ and $\Delta \mathrm{b}$ values were different among the groups, the complete color change in the specimen, represented by $\Delta \mathrm{E}$, did not differ. However, the values are high when compared to the ones found by IMAI et al. (2013) [10] after the staining of indirect resins in tea, and the values found by PIRES DE SOUZA et al., 2007 [27], but without staining.

Composite resin suffers hygroscopic expansion in the first 24 hours [27, 28], potentially causing intrinsic staining, which leads to a different degree of light dispersion when in smaller and bigger particles [29]. According to DOMINGOS et al. 2011 [6], the composition and characteristics of resin particles have a direct impact on the susceptibility to staining. The composite resin used in the study (Charisma ${ }^{\text {TM }}$ Diamond, Hanau, Germany) presents the base of TCD-DI-HEA of UDMA. The UDMA is more resistant to staining than BisGMA, considering it is more resistant to sorption and solubility [6]. CATELAN et al. (2011) [30] performed a study with composite resin samples, which were stored in deionized water after production, differing only in the storage time. In such study, the samples spent only two minutes immersed in deionized water, while in the present study, the samples remained for 24 hours, agreeing with the study by NASSIM et al. (2010) [31], considering that water sorption occurs more intensely over the first hours after polymerization.

Polishing was performed after the samples spent 24 hours immersed in deionized water, with abrasive rubbers for composite resin, for five seconds on each side. This procedure was performed to simulate the execution of the clinical steps usually performed, preventing that the use of the polyester matrix strip would leave the surface extremely smooth due to the outbreak of the organic matrix $[32,33]$. The same methodological step occurred in the studies by PLASTER et al. (2016) [34], SELIG et al. (2015) [35], and ERDEMIR et al. (2012) [36], only varying the time and polishing mechanism.

Besides resin composition, the application of high light intensity is recommended to optimize the hydrolytic stability and the color stability of composite resins [10, 37]. A study performed by YAN-FANG (2002) [38] showed that composite resins suffer a higher degree of staining when they are underpolymerized. However, the author did not report the levels of power density related to an inadequate polymerization of the composite resin and its consequent losses of aesthetic and functional properties. The photopolymerizer used in the present study was the Valo Colors Fucsia (Ultradent, South Jordan, USA). This appliance was selected for presenting an extensive energy power, reaching up to $3200 \mathrm{~mW} / \mathrm{cm}^{2}$, a collimated light beam, according to the manufacturer, thus making its trajectory more precise and preventing the energy dissipation that allows standardization at the moment of polymerizing the specimens for each group.

Staining was performed with an instant coffee solution. According to AWLIYA, NAHEDH (2012) [39] and LEMPEL et al. (2017) [40], coffee is one of the beverages mostly associated with the staining of dental restorative materials, therefore, it was the dye solution selected to assess the color stability of the composite resin, besides being a widespread and popular beverage. The staining potential of composite resins is a consensus in the literature, considered a multifactorial occurrence caused mainly by structural failures in composite resins associated with the frequent ingestion of foods rich in pigments [30, 31, 38, 41].

The quantitative assessment of $\Delta \mathrm{L}, \Delta \mathrm{a}$, and $\Delta \mathrm{b}$ was performed, as in other studies [3,10,15, 42], using a spectrophotometer, because of the subjectivity of the color assessment. This subjectivity is a result of some factors such as the position of the observer and the object under observation concerning the light, as well as the emotional condition of the observer and the aging of the object [43].

This is the first study in the literature that shows the influence of different power densities on the color of composite resins. The great majority of studies [3, 10, 15, 42] focuses, however, on assessing polymerization shrinkage. Nevertheless, it is worth noting the need for further in vitro studies in this direction, aiming to optimize the performance of resin materials.

\section{CONCLUSIONS}

The use of medium and low power density results in a more reddish and bluish composite resin. A high power of density and immersion in coffee does not change the color of the nanoparticulate composite resin, in the short term. 


\section{BIBLIOGRAPHY}

[1] DE CÁSSIA ROMANO, B., SOTO-MONTERO, J., RUEGGEBERG, F.A., et al. "Effects of extending duration of exposure to curing light and different measurement methods on depth-of-cure analyses of conventional and bulk-fill composites". doi: 10.1111/eos.12703. Epub 2020 Jun 5. PMID: 32502304. European Journal of Oral Sciences, v. 128, n. 4, pp. 336-344, Aug. 2020.

[2] ATTAR, N. "The effect of finishing and polishing procedures on the surface roughness of composite resin materials". PMID: 17211502. The Journal of Contemporary Dental Practice, v. 8, n. 1, pp. 27-35, Jan. 2007.

[3] NAKAZAWA, M. "Color stability of indirect composite materials polymerized with different polymerization systems". doi: 10.2334/josnusd.51.267. Journal of Oral Science., v. 51, n. 2, pp. 267-273, Jun. 2009. [4] DOUGLAS, R.D. "Color stability of new-generation indirect resins for prosthodontic application". doi: 10.1016/s0022-3913(00)80008-6. Journal of Prosthetic Dentistry, v. 83, n. 2, pp. 166-170, Feb. 2000.

[5] BAGHERI, R., BURROW, M.F., TYAS, M. "Influence of food-simulating solutions and surface finish on susceptibility to staining of aesthetic restorative materials". doi: 10.1016/j.jdent.2004.10.018. Journal of Dentistry, v. 33, n. 5, pp. 389-398, May. 2005.

[6] DOMINGOS, P.A. et al. "Composite resin color stability: influence of light sources and immersion media”. doi: 10.1590/s1678-77572011000300005. Journal of Applied Oral Science, v. 19, n. 3, pp. 204-211, May-Jun. 2011.

[7] MUTLU-SAGESEN, L., et al. "Color stability of a dental composite after immersion in various media". doi: 10.4012/dmj.24.382. Dental Materials Journal, v. 24, n. 3, pp. 382-390, Sep. 2005.

[8] SILVA, M.F., DIAS, M.F., LINS-FILHO, P.C., et al. "Color stability of Bulk-Fill composite restorations". doi: 10.4317/jced.57579. PMID: 33262876; PMCID: PMC7680568. Journal of Clinical and Experimental Dentistry, v. 12, n. 11, pp. e1086-e1090, Nov. 2020.

[9] KWON, T.Y., et al. "Cure mechanisms in materials for use in esthetic dentistry". doi: 10.1111/j.20411626.2012.00114.x. Journal of Investigative and Clinical Dentistry, v. 3, n. 1, pp. 3-16, Feb. 2012.

[10] IMAI, H., et al. "The influence of polymerization conditions on color stability of three indirect composite materials". doi: 10.2334/josnusd.55.51. Journal of Oral Science., v. 55, n. 1, pp. 51-55, Mar. 2013.

[11] SULIMAN, A.A., ABDO, A.A., ELMASMARI, H.A. "Training and experience effect on light-curing efficiency by dental practitioners". PMID: 32064625. doi: 10.1002/jdd.12113. Epub 2020 Feb 17. Journal of Dental Education, v. 84, n. 6, pp. 652-659, Jun. 2020.

[12] STOBER, T., GILDE H., LENZ P. "Color stability of highly filled composite resin materials for facings”. doi: 10.1016/s0109-5641(00)00065-8. Dental Materials Journal., v. 17, n. 1, pp. 87-94, Jan. 2001.

[13] PREZOTTO, G.F.S., LIMA, W.S., VITTI, R.P., et al. "Light-curing units, photoinitiators system, and monomers on physico-mechanical properties of experimental composite resins". doi: 10.1590/S1517707620200003.1093.Revista Matéria, v. 25, n. 3, Sep. 2020.

[14] TANOUE, N., et al. "Influence of acidulated phosphate fluoride solution on the color stability of indirect composites". doi: 10.1016/j.prosdent.2004.07.008. Journal of Prosthetic Dentistry, v. 92, n. 4, pp. 343347, Oct. 2004.

[15] FONSECA, A.S., et al. "Effect of monomer type on the CC degree of conversion, water sorption and solubility and color stability of model dental composites". Doi: 10.1016/j.dental.2017.01.01. Dental Materials Journal, v. 33, pp. 394-401. 2017.

[16] IMAZATO S., et al. "Relationship between the degree of conversion and internal discoloration of lightactivated composite". doi: 10.4012/dmj.14.23. Dental Materials Journal, v. 14, n. 1, pp. 23-30, Jun. 1995.

[17] OZAN, G., SANCAKLI, H.S., TIRYAKI, M., et al. "Effect of Light Curing Modes on the Color Stability of a Nanohybrid Composite Immersed in Different Beverages". doi: 10.15517/IJDS.2020.38726. ODOVTOS International Journal of Dental Sciences, v. 22, n. 2, Aug. 2019.

[18] KIM, S.H., LEE, Y.K. "Changes in color and color coordinates of an indirect resin composite during curing cycle”. doi: 10.1016/j.jdent.2008.01.013. Journal of Dentistry, v. 36, n. 5, pp. 337-342, May. 2008.

[19] WILLIAN, F.F., OLIVEIRA, W.S., MIRANDA, M.E., et al. "Polymerization depths of conventional and bulk fill composites photoactivated by different methods". doi: 10.1590/S1517-707620200003.1124. Revista Matéria, v. 25, n. 3, Sep. 2020. 
[20] MOUSAVINASAB, S.M., et al. "Evaluation of light curing distance and mylar strips color on surface hardness of two different dental composite resins". doi: 10.2174/1874210601408010144. The Open Dentistry Journal, v. 8, pp. 144-147, Sep. 2014.

[21] FRANCO, E.B., LOPES, I.G. "Conceitos atuais na polimerização de sistemas restauradores resinosos". Biodonto., v. 1, n. 2, pp. 10-59. 2003.

[22] USUMEZ, A., OZTURK, N., OZTURK, B. "Two-year color changes of light-cured composites: influence of different light-curing units”. PMID: 16268402. Operative Dentistry, v. 30, n. 5, pp. 655-660, SepOct. 2005.

[23] MICALI, B., BASTING, R.T. "Effectiveness of composite resin polymerization using light-emitting diodes (LEDs) or halogen-based light-curing units". doi: 10.1590/s1806-83242004000300016. Brazilian Oral Research, v. 18, n. 3, pp. 266-270, Jul-Sep. 2004.

[24] AGUIAR, F.H., GEORGETTO, M.H., SOARES, G.P., et al. "Effect of different light-curing modes on degree of conversion, staining susceptibility and stain's retention using different beverages in a nanofilled composite resin". doi: 10.1111/j.1708-8240.2011.00406.x. PMID: 21477037. Journal of Esthetic and Restorative Dentistry, v. 23, n. 2, pp. 106-114, Apr. 2011.

[25] AYESHA SWARN. Commentary. Effect of different light-curing modes on degree of conversion, staining susceptibility and stain's retention using different beverages in a nanofilled composite resin. doi: 10.1111/j.1708-8240.2011.00407.x. Journal of Esthetic and Restorative Dentistry, v. 23, n. 2, pp. 115, Apr. 2011.

[26] SOARES, L.E.S., et al. "FT-Raman spectroscopy study of organic matrix degradation in nanofilled resin composite." Microscopy and microanalysis: the official journal of Microscopy Society of America, Microbeam Analysis Society, doi:10.1017/S1431927612014225 Microscopical Society of Canada, v. 19, n. 2, pp. 327-334, 2013.

[27] PIRES-DE-SOUZA, FDE. C., et al. "Color stability of composites subjected to accelerated aging after curing using either a halogen or a light emitting diode source". doi: 10.1590/s0103-64402007000200006.

Brazilian Dental Journal, v. 18, n. 2. 2007.

[28] CIE-COLOURIMETRY. "Official recommendations of the international commission on illumination Publication CIE (supplement No. 21)”. Paris: Bureau Central de la CIE; 15-30. 1978.

[29] SHIN, D.H., RAWLS, H.R. "Degree of conversion and color stability of the light curing resin with new photoinitiator systems". doi: 10.1016/j.dental.2009.03.004. Dental Materials, v. 25, n. 8, Aug. 2009.

[30] CATELAN, A., et al. "Color stability of sealed composite resin restorative materials after ultraviolet artificial aging and immersion in staining solutions". doi: 10.1016/S0022-3913(11)60038-3. Journal of Prosthetic Dentistry, v. 105, n. 4, pp. 236-241, Apr. 2011.

[31] NASIM, I., et al. "Color stability of microfilled, microhybrid and nanocomposite resins--an in vitro study". doi: 10.1016/j.jdent.2010.05.020. Journal of Dentistry, v. 38 (Suppl 2), pp. e137-142. 2010.

[32] YAP, A.U., LYE, K.W., SAU, C.W. "Surface characteristics of tooth-colored restoratives polished utilizing different polishing systems". PMID: 9610323. Operative Dentistry, v. 22, n. 6, pp. 260-265, Nov-Dec. 1997.

[33] YAP, A.U., et al. "Finishing/polishing of composite and compomer restoratives: effectiveness of onestep systems". PMID: 15195727. Operative Dentistry, v. 29, n. 3, pp. 275-279, May-Jun. 2004.

[34] PLASTER, S.C., et al. "Efeito de diferentes fotopolimerizadores e meio de imersão na rugosidade e na cor de um compósito nanoparticulado". Revista de Odontologia da UNESP., v. 45, pp. 283-289. 2016.

[35] SELIG, D., et al. "Examining exposure reciprocity in a resin based composite using high irradiance levels and real-time degree of conversion values". doi: 10.1016/j.dental.2015.02.010. Dental Materials, v. 31, n. 5, pp. 583-593, May. 2015.

[36] ERDEMIR, U., YILDIZ, E., EREN, M.M. "Effects of sports drinks on color stability of nanofilled and microhybrid composites after long-term immersion". doi: 10.1016/j.jdent.2012.06.002. Journal of Dentistry, v. 40 (Suppl 2), pp. 55-63, Dec. 2012.

[37] KOUROS, P., DIONYSOPOULOS, D., DELIGIANNI, A., et al. "Evaluation of photopolymerization efficacy and temperature rise of a composite resin using a blue diode laser $(445 \mathrm{~nm})$ ". doi:

10.1111/eos.12742. Epub 2020 Oct 23. PMID: 33094854. European Journal of Oral Science, v. 128, n. 6, pp. 535-541, Dec. 2020.

[38] REN, Y.F., et al. "Effects of common beverage colorants on color stability of dental composite resins: the utility of a thermocycling stain challenge model in vitro". doi: 10.1016/j.jdent.2012.04.017. Journal of Dentistry, v. 40 (Suppl 1), pp. e48-56, Jul. 2012. 
[39] AL-NAHEDH, H.N., AWLIYA, W.Y. "The effectiveness of four methods for stain removal from direct resin-based composite restorative materials". doi: 10.1016/j.sdentj.2013.02.002. Saudi Dental Journal, 2013 Apr;25(2):61-7.

[40] LEMPEL, E., et al. "Direct resin composite restorations for fractured maxillary teeth and diastema closure: A 7 years retrospective evaluation of survival and influencing factors". doi: 10.1016/j.dental.2017.02.001. Dental Materials, v. 33, n. 4, pp. 467-476, Apr. 2017.

[41] ELDIWANY, M., FRIEDL, K.H., POWERS, J.M. "Color stability of light-cured and post-cured composites”. PMID: 7576383. American Journal of Dentistry, v. 8, n. 4, pp. 179-181, Aug. 1995.

[42] OLIVEIRA, D.C., et al. "Color stability and polymerization behavior of direct esthetic restorations". doi: 10.1111/jerd.12113. Journal of Esthetic and Restorative Dentistry, v. 26, n. 4, pp. 288-295, Jul-Aug. 2014.

[43] YANNIKAKIS, S.A., et al. "Color stability of provisional resin restorative materials". doi: 10.1016/s0022-3913(98)70028-9. Journal of Prosthetic Dentistry, v. 80, n. 5, pp. 533-539, Nov. 1998.

\section{ORCID}

Brunelly Cardoso de Jesus Santos Jefferson Chaves Moreira Yasmin Alves do Nascimento Daniel Maranha da Rocha Adriano Augusto Melo de Mendonça Lycia Gardenia dos Santos Oliveira Eduardo Bresciani Daiana Conceição Broll Repeke Flavia Pardo Salata Nahsan
https://orcid.org/0000-0003-1441-416X https://orcid.org/0000-0003-4276-4810 https://orcid.org/0000-0003-4840-7830 https://orcid.org/0000-0003-1825-8168 https://orcid.org/0000-0002-2365-5718 https://orcid.org/0000-0001-7681-2871 https://orcid.org/0000-0001-9299-8792 https://orcid.org/0000-0001-5824-5244 https://orcid.org/0000-0002-3547-8886 